\title{
Mobile WiMAX and It Comparison with other Next Generation Wireless Network Technologies
}

\author{
Deman Kosale $^{1}$, H.R.Suryawanshi ${ }^{2}$, Maheedhar Dubey ${ }^{3}$ \\ Assistant Professor, Electrical Engineering, VEC, Lakhanpur, Ambikapur, India ${ }^{1,3}$ \\ Assistant Professor, Mathematics, VEC, Lakhanpur, Ambikapur, India ${ }^{2}$
}

\begin{abstract}
In the next generation networks (4G) for Wireless Metropolitan area technology, the Mobile Wi-max (Wireless Interoperability Wireless Access) is one of the outstanding technologies that have promised to offer broadband wireless access (BWA) over long distance. The Mobile WiMAX was successfully adopted by ITU (International Telecommunication Union) as one of the IMT2000 (International mobile Telecommunications) technologies in November-2007. Mobile WiMAX, based on the IEEE 802.16e standard (release 1), supports a several types of handovers and allows fully mobility of users. Today the IEEE 802.16 Working Group (WG) has formed the IEEE $802.16 \mathrm{~m}$ (release 2) and IEEE 802.16j. The IEEE 802.16j will provide relay functionality and IEEE 802.16m (Advance Air Interface) will provide high data rates and additional functionalities to meet the requirements for IMT-Advanced defined by ITU-R (ITU-Radio communication Sector) for 4G system. Another technology considered by IMT-Advanced for the 4G Radio Access Technology is LTE-Advanced. This paper provides vast overview of IEEE 802.16e and its comparison with other wireless technologies.
\end{abstract}

Keywords: Mobile WiMAX, IEEE 802.16e, PHY-layer, MAC-layer, Handover, IEEE 802.16m.

\section{INTRODUCTION}

Today the increasing demand for mobile broadband, internet and multimedia application a user can use all these services anytime and anywhere. IEEE802.16 [1] WG (Working Group) provide a solution for broadband wireless access (BWA) technologies i.e. called IEEE 802.16e or Mobile WiMAX. Mobile WiMAX is one of the outstanding BWA technologies that can provide high data rate and cover wider area than WLAN system. Mobile WiMAX combines both OFDMA (Orthogonal Frequency-Division Multiple Access) and advance MIMO (Multiple Input and Multiple Output) technologies.

The IEEE 802.16 [1] WG established by the IEEE standards board in 1999 has developed and published several version of Air Interface Standard for Wireless Metropolitan Area Networks (WMANs). The IEEE WG first standard was published in 2001, i.e. IEEE 802.16 standard providing Air Interface for fixed BWA system in 10-66 GHz band with a theoretical maximum bandwidth of $120 \mathrm{Mb} / \mathrm{s}$ and maximum transmission range $50 \mathrm{Km}$. This standard only supports lineof-sight (LOS) transmission and thus does not seem to favor deployment in urban areas. A variant of the standard, IEEE 802.16 (i.e. IEEE $802.16 \mathrm{a}, .16 \mathrm{~b}, .16 \mathrm{c}, .16 \mathrm{~d}$ ) that support only for fixed BWA system, not for mobility. This is the main problems in the earlier draft of IEEE 802.16 but the IEEE 802.16 WG is solve this problem by developing a standard that is IEEE 802.16e [2] is called Mobile WiMAX (WiMAX).

The WiMAX adopt OFDMA and SOFDMA (Scalable OFDMA) at the physical layers for easy and fast transmission. The IEEE 802.16e [2] amendment include many new features and functionality needed to support enhanced quality of service (QoS) and mobility. The QoS are providing by MAC layers in WiMAX. IEEE 802.16e is fully supported via multimedia transmission with different QoS requirements through the use of scheduling mechanisms. The increasing demand of multimedia applications in the internet, IEEE 802.16 provides new wireless services such as multimedia streaming, real-time surveillance, Voice over IP (VoIP) and multimedia conferencing. The WiMAX adds significant enhancement [3].

(1) PHY layers adopt OFDMA with scalable bandwidth from 1.25-20 MHz.

(2) It uses of MIMO antenna technologies (i.e. Adaptive antenna system, AAS) to supports both downlink and uplink high data rates.

(3) It improves multipath performance in NLOS environments by using OFDMA technologies.

(4) Its use S-OFDMA to support by adjusting the FFT (Fast Fourier Transform) size from 128 to 512, 1024, 2048, to supports channel bandwidth of $1.25 \mathrm{MHz}, 5 \mathrm{MHz}, 10 \mathrm{MHz}$ and $20 \mathrm{MHz}$ respectively.

TABLE I. IEEE 802.16 STANDARDS

\begin{tabular}{|l|l|l|}
\hline Standard & Description & Status \\
\hline $802.16-2001$ & $\begin{array}{l}\text { Fixed Broad Band } \\
\text { Wireless Access (10-63 } \\
\text { GHz) }\end{array}$ & Supersede \\
\hline $802.16 .2-2001$ & $\begin{array}{l}\text { Recommended Practice } \\
\text { for Coexistence }\end{array}$ & Supersede \\
\hline $802.16 \mathrm{c}-2002$ & $\begin{array}{l}\text { System Profile for 10- } \\
63 \mathrm{GHz}\end{array}$ & Supersede \\
\hline
\end{tabular}




\begin{tabular}{|c|c|c|}
\hline $802.16 a-2003$ & $\begin{array}{l}\text { Physical Layer and MAC } \\
\text { definition for } 3-11 \mathrm{GHz}\end{array}$ & Supersede \\
\hline P802.16c & $\begin{array}{l}\text { License exempt } \\
\text { Frequencies (Project } \\
\text { withdrawn) }\end{array}$ & Withdrawn \\
\hline P802.16d & $\begin{array}{l}\text { Maintenance and system } \\
\text { profile for } 2-11 \mathrm{GHz} \\
\text { (Project merged into } \\
802.16-2004 \text { ) }\end{array}$ & Merged \\
\hline $802.16-2004$ & $\begin{array}{l}\text { Air interference with } \\
\text { fixed Broad Band } \\
\text { Wireless Access system } \\
\text { (Roll up of } 802.16-2001 \text {, } \\
802.16 \mathrm{a}, 802.16 \mathrm{c} \text {, and } \\
\text { P802.16d) }\end{array}$ & Superseded \\
\hline P802.16.2a & $\begin{array}{l}\text { Coexistence with } 2-11 \\
\text { GHz and } 23.5-43.5 \mathrm{GHz} \\
\text { (Project merged into } \\
802.16,2-2004) .\end{array}$ & Merged \\
\hline $802.16 .2-2004$ & $\begin{array}{l}\text { Recommended Practice } \\
\text { for Coexistence } \\
\text { (Maintenance and roll up } \\
\text { of } 802.16 .2-2001 \text { and } \\
\text { P802.16.2a) }\end{array}$ & Current \\
\hline $802.16 f-2005$ & MIB for $802.16-2004$ & Superseded \\
\hline $\begin{array}{l}802.16- \\
2004 / \text { core } 1- \\
2005\end{array}$ & $\begin{array}{l}\text { Correction for fixed } \\
\text { operations (Co-published } \\
\text { with } 802.16 \mathrm{e}-2005) \text {. }\end{array}$ & Superseded \\
\hline $802.16 \mathrm{e}-2005$ & $\begin{array}{l}\text { Mobile Broad Band } \\
\text { Wireless Access } \\
\text { System. }\end{array}$ & Superseded \\
\hline $802.16 \mathrm{k}-2007$ & $\begin{array}{l}\text { Bridging of } 802.16 \text { (An } \\
\text { amendment to IEEE } \\
802.1 \mathrm{D})\end{array}$ & Current \\
\hline $802.16 \mathrm{~g}-2007$ & $\begin{array}{l}\text { Management plane } \\
\text { Procedure and System }\end{array}$ & Superseded \\
\hline P802.16i & $\begin{array}{l}\text { Mobile Management } \\
\text { Information Base (Project } \\
\text { Merged into 802.16- } \\
2009 \text { ) }\end{array}$ & Merged \\
\hline 802.16-2009 & $\begin{array}{l}\text { Air interface for fixed } \\
\text { and mobile Broadband } \\
\text { wireless access system } \\
\text { (Rollup of } 802.16-2004 \text {, } \\
802.16-2004 / \text { Core } 1 \text {, } \\
802.16 \text { e, } 802.16 \text {, } \\
802.16 \text { g and P802.16i) }\end{array}$ & Current \\
\hline $802.16 \mathrm{j}-2009$ & Multihop Relay & Current \\
\hline $802.16 \mathrm{~h}-2010$ & $\begin{array}{l}\text { Improved Coexistence } \\
\text { Mechanism for } \\
\text { Latescence Exempt } \\
\text { Operation }\end{array}$ & Current \\
\hline P802.16m & $\begin{array}{l}\text { Advance Air Interface } \\
\text { with Data Rate } 100 \mathrm{Mb} / \mathrm{s} \\
\text { Mobile and } 1 \mathrm{~Gb} / \mathrm{s} \text { fixed. }\end{array}$ & In progress \\
\hline P802.16n & $\begin{array}{l}\text { Higher Reliability } \\
\text { Networks. }\end{array}$ & In progress \\
\hline
\end{tabular}

\section{PHY LAYER OF IEEE 802.16e}

IEEE 802.16e air interface adopts OFDMA for improved multipath performance in NLOS environments. The OFDMA in PHY layer of mobile WiMAX based on scalable-OFDMA i.e. called SOFDMA [4]. The SOFDMA support a wide range of operating scalable channel bandwidths from 1.25 to 20 $\mathrm{MHz}$ to flexibly address the need for various spectrum allocation and application requirement, when the operating bandwidth increase the FFT size is also increased to maintain a fixed subcarrier frequency spacing of $10.94 \mathrm{KHz}$. This ensures a fixed OFDMA symbol duration. Since the basic resource unit (i.e. the OFDMA symbol duration) is fixed, the impact of bandwidth scaling is minimized to the upper layers [5], [6]. Table II shows the relevant parameters for the OFDMA PHY layer [5], [6].

TABLE II. PARAMETERS FOR OFDMA PHY

\begin{tabular}{|l|l|l|l|l|}
\hline Parameter & \multicolumn{4}{|l|}{ Value } \\
\hline FFT Size & 128 & 512 & 1024 & 2048 \\
\hline Channel Bandwidth (MHz) & 1.25 & 5 & 10 & 20 \\
\hline $\begin{array}{l}\text { Subcarrier Frequency } \\
\text { Spacing (KHz) }\end{array}$ & 10.94 \\
\hline Useful Symbol Period & 91.4 \\
\hline Guard Time & $1 / 32,1 / 6,1 / 8,1 / 4$ \\
\hline
\end{tabular}

In the Mobile WiMAX for producing higher code rates, the channel coding stage includes randomization; convolution coding (native code rate is $1 / 2$ ) and puncturing to produce higher code rates. The modulation scheme used in Mobile WiMAX is QPSK (Quadrature Phase Shift Keying), 16QAM (Quadrature Amplitude Modulation) or 64QAM. The modulation data are mapped by segmenting the sequence of modulated symbols into a sequence of slots. A guard interval is also inserted at this stage [5], [6].

\section{MAC LAYAER IN WIMAX}

Figure 1 shows the reference model of IEEE 802.16 layers [3]. In this figure the MAC layer consists of three sub layers: (1) The service-specific convergence sub layers (CS), (2) MAC common part sub layer (MAC CPS) and (3) Security sub layer

\section{F. Service-Specific Convergence Sub layer (CS):}

The main function of CS is to transform or map external data from the upper layers into appropriate MAC service data units (SDUs) for the MAC CPS. This includes classification of external data with the proper MAC service flow identifier (SFID) and connection identifier (CID). An SDU is the basic data unit exchanged between two adjacent protocol layers.

\section{G. MAC Common Part Sub layer (MAC CPS):}

The MAC CPS provides the core functionality for system access, allocation of bandwidth, and connection establishment and maintenance. This sub layer also handles the QoS aspect of data transmission.

\section{H. Security Sub layer:}

The security sub layer provides functionalities such as authentication, secure key exchange, and encryption. For the PHY layer, the standard supports multiple PHY specifications, each handling a particular frequency range. IEEE 802.16e provides Point-to-Multipoint (PMP) modes of operation.

D. Point-to-Multipoint: WiMAX is connection oriented technology which means that all data service are mapped to a connection between the SS and The BS. In other words, a connection between the entities must be established before 
any uncast traffic can be transmitted. The DL direction from BS to SS operates on a PMP basis in which a central BS is able to provide independent, frequency-separated sectors and serve multiple SSs located in the sectors [7].

E. MAC Management messages: The management message are designed for controlling actions at SS, RS or BS on request/ response/ acknowledgment basis: Some of the events triggered or executed by the management message exchanges are the following [2].

1 Network entry and registration.

2 Handover.

3 Privacy service addition, modification and removal.

4 UL(Uplink) and DL(Downlink) physical channel

Description on DCD/UCD messages.

5 Delivery of UL and DL user access information on DL-/UL-MAP messages.

6 Multicast polling.

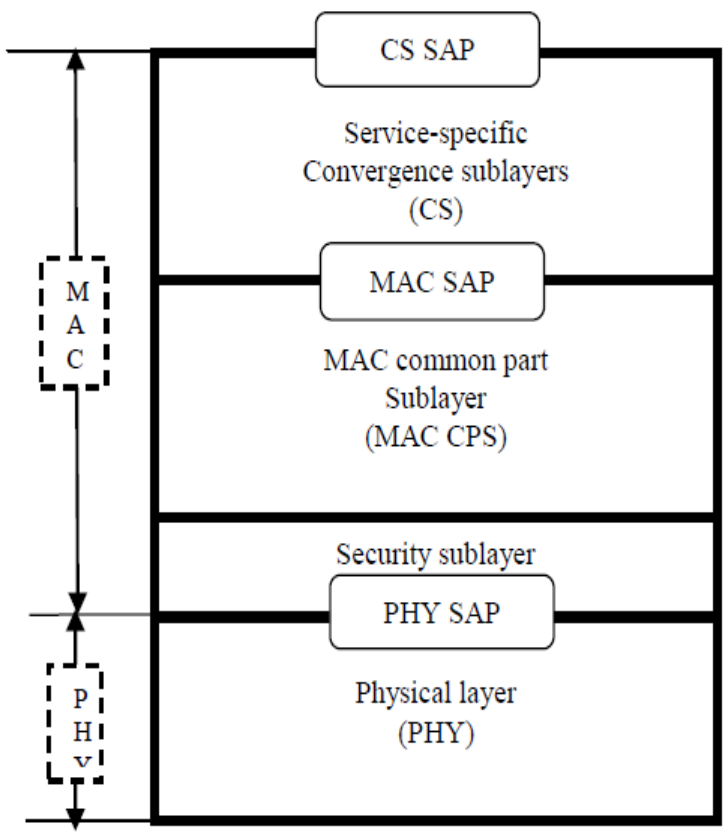

Figure.1 IEEE 802.16 Reference Model

\section{HAND OVER IN MOBILE WIMAX}

IEEE 802.16WG has defined three types of handover or IEEE 802.16e technologies [2]: the Hard Handover (HHO), the Fast Base Station Switching (FBSS), and the Micro Diversity Handover (MDHO). The first one is required while the others are optional types.

In WiMAX a handover initiation decision by a wireless terminal or BS is dependent on the Received Signal Strength (RSS) from the current serving BS (SBS) and neighboring BS (NBS). The MS and the SBS both decide on when to initiate a handover activity whenever the RSS from the SBS drops below a certain threshold, which might hamper an ongoing communication session, the MS goes for a handover with one of the chosen NBS, called the target BS(TBS).

\section{Hard Handover}

The Hard handover is a process to change the serving BS using a "break-before-make" way in other words connection to the old BS is broken before a new BS is connected. The process of HHO in IEEE 802.16e is broadly divided into Network Topology Acquisition Phase (NTAP) and Actual Handover Phase (AHOP).

\section{J. Micro Diversity Handover and Fast Base Station Switching}

The MDHO and the FBSS are consider as soft handover method and both are optional handover scheme for the Mobile WiMAX and therefore needs to be supported by both the MS and the BS. The MS keep a list of BSs capable to the MDHO on its coverage area. This group is called Diversity Set (DS), or in some source in Active Set (AS). There is always one BS in the DS that is defined as an Anchor BS (ABS). In the MDHO the MS is able to communicate in DL and UL with all the BSs in the DS simultaneously instead of only one. In the FBSS the MS communicate only with one ABS over UL and DL channel. So, signal strength of neighboring BSs are continuously monitored by each MS for efficient updating of its DS and ABS.

\section{$K$. Comparison Between $\mathrm{HHO}$ and $\mathrm{MDHO}$ and FBSS}

The HHO mechanism used in now day beyond 3G (B3G) technologies but it cannot handle voice-centric application with high speed mobility. On the other hand the MHDO and FBSS are provide full seamless mobility at high speed (up to $120 \mathrm{~km} / \mathrm{s}$ ) with very low (less than 1\%) packet loss, very fast switching and low handover latency (less then 50ms). These two handover technologies can also supports high speed realtime voice centric application like VoIP and provide better performance with respect to multi-access interference, flexibility and coverage than their CDMA(Code Division Multiple Access) competitors do [8]. It means the MDHO and the FBSS provide better handover performance in comparison to $\mathrm{HHO}$, there is still a long way to go before adequate support measures for these two techniques can be developed and deployed in WiMAX networks

TABLE. III COMPARISON OF THE MWIMAX HANOVER TECHNIQUES

\begin{tabular}{|l|l|l|l|}
\hline Parameter & Handover & MDHO & FBSS \\
\hline Latency & High & Low & Medium \\
\hline Complexity & Low & High & Medium \\
\hline Reliability & Low & High & Medium \\
\hline $\begin{array}{l}\text { Packet } \\
\text { Losses }\end{array}$ & High & Low & Low \\
\hline Cost & Low & High & Medium \\
\hline $\begin{array}{l}\text { Support for } \\
\text { delay } \\
\text { sensitive } \\
\text { Application }\end{array}$ & Low & High & High \\
\hline Speed & Low & High & Medium \\
\hline Link quality & Low & High & Medium \\
\hline
\end{tabular}


In the WiMAX handover enhanced by integrating fixed relay station in WiMAX networks [9]. In this paper author proposed fast $\mathrm{HO}$ scheme called Passport Handover along with Transport CID(Connection Identifier) mapping strategy for real-time application and by this method the HO latency for both downlink and uplink service is greatly reduced [10]. In this paper author discus main issues in WiMAX handover and also has highlight those cross-layer (L2+L3) challenges that demand more attention [8]. In this paper proposed a new metrology for reduce latency for both DL and UL during scan and handover procedure [11].

\section{ADVANCE MWIMAX AND COMPARISON WITH OTHER TECHNOLOGIES}

Today, IEEE 802.16 WG is developing two new standards that is $802.16 \mathrm{j}$ and $802.16 \mathrm{~m} \mathrm{[12],} \mathrm{[13].} \mathrm{The} 802.16 \mathrm{j}$ will provide relay functionality and $802.16 \mathrm{~m}$ (Advance Air Interface) will provide higher data rates and additional functionalities to meet the requirements for IMT-Advance defined by ITU-R for $4 \mathrm{G}$ system [14].

The 4G wireless technology describes mobile wireless services which have been defined by the ITU-R and IMTAdvanced. These are mobile system that include the new capabilities of IMT that go beyond those of IMT-200. Long Term Evolution-Advanced (LTE-Advanced) [15] and IEEE $802.16 \mathrm{~m}$ are the two main candidate technologies submitted for IMT-advanced certification. In order to meet IMTAdvanced goals, several enhancement and new capabilities are being studied for inclusion source more efficiently, increase capability, improve reliability in highly mobile environments, and accommodate users with different requirements. The goal is to reduce overhead, improve flexibility and facilitate channel estimation. The IEEE $802.16 \mathrm{~m}$ allows handover with service continuity for Radio Access Technologies (specific interest being paid on IEEE 802.11, 3GPP, GSM/EDGE, UTRA, E-UTRA and 3GPP2 CDMA2000) and support of IEEE 802.21 Media Independent Handover (MIH) standard. IEEE 802.21: Media Independent Handover that enable the optimization of handover between heterogeneous IEEE 802 networks and facilities handover between IEEE 802 networks and cellular networks.

IEEE $802.16 \mathrm{~m}$ will comprise three documents: A system Requirement Document (SRD) [16], a System Description Document (EMD), and an Evaluation Methodology Document (EMD) [17]. As its name suggests, the System Requirements Document contains high-level requirements for $802.16 \mathrm{~m}$ - compliment system, including, among others, rates throughput, coverage, mobility support, operating bandwidths and frequency, QoS, latency, handover and security. The main goal is to meet the cellular layer demands of IMTAdvanced and, at same the time, support latency WMANOFDMA equipment. A list of some of main requirements for IEEE $802.16 \mathrm{~m}$ is given in Table $\mathrm{V}$. These requirements are compared with IEEE 802.16e, the latency standard for Mobile WiMAX.
TABLE IV. .IMPORTANT FEATURES AND REQUIREMENTS OF MOBILE WIMAX STANDARDS

\begin{tabular}{|c|c|c|}
\hline Requirement & IEEE 802.16e & IEEE $802.16 \mathrm{~m}$ \\
\hline $\begin{array}{l}\text { Aggregate Data } \\
\text { Rate }\end{array}$ & $63 \mathrm{Mbps}$ & $\begin{array}{l}100 \text { Mbps for } \\
\text { mobile station, } \\
1 \text { Gbps for fixed }\end{array}$ \\
\hline $\begin{array}{l}\text { Operating Radio } \\
\text { Frequency }\end{array}$ & $\begin{array}{l}2.3 \mathrm{GHz}, 2.5- \\
2.7 \mathrm{GHz}, 3.5 \\
\mathrm{GHz}\end{array}$ & $<6 \mathrm{GHz}$ \\
\hline MIMO Support & $\begin{array}{l}\text { TDD and } \\
\text { FDD }\end{array}$ & $\begin{array}{l}4 \text { or } 8 \text { stream. No } \\
\text { limit on antenna }\end{array}$ \\
\hline Coverage & $10 \mathrm{Km}$ & $\begin{array}{l}3 \mathrm{Km}, 5-30 \mathrm{Km},, 30 \\
-100 \mathrm{Km} \text { depending } \\
\text { on scenario }\end{array}$ \\
\hline $\begin{array}{l}\text { HO Inter- } \\
\text { frequency } \\
\text { Interruption Time }\end{array}$ & $30-50 \mathrm{~ms}$ & $30 \mathrm{~ms}$ \\
\hline $\begin{array}{l}\text { HO Intra- } \\
\text { frequency } \\
\text { Interruption Time }\end{array}$ & Not specified & $100 \mathrm{~ms}$ \\
\hline $\begin{array}{l}\text { HO between } \\
802.16 \text { Standard } \\
\text { (For } \\
\text { corresponding } \\
\text { Mobile station) }\end{array}$ & $\begin{array}{l}\text { From } 802.16 \mathrm{e} \\
\text { serving BS to } \\
802.16 \mathrm{e} \\
\text { target BS }\end{array}$ & $\begin{array}{l}\text { From legacy SBS to } \\
\text { legacy TBS } \\
\text { From } 802.16 \mathrm{~m} \mathrm{SBS} \\
\text { to ligancy TBS } \\
\text { from legacy } 802.16 \\
\text { SBS to } 802.16 \mathrm{TBS} \\
\text { From } 802.16 \mathrm{~m} \text { SBS } \\
\text { to } 802.16 \mathrm{~m} \text { TSB }\end{array}$ \\
\hline $\begin{array}{l}\text { HO with other } \\
\text { Technologies }\end{array}$ & Not specified & $\begin{array}{l}\text { IEEE 802.11, } \\
\text { 3GPP2, } \\
\text { GSM/EDGE, (E-) } \\
\text { UTRAN (LTE } \\
\text { TDD) Using } 801.21 \\
\text { MIH }\end{array}$ \\
\hline Mobility Speed & $\begin{array}{l}\text { Vehicular } 120 \\
\mathrm{~km} / \mathrm{h}\end{array}$ & $\begin{array}{l}\text { Indoor } 10 \mathrm{~km} / \mathrm{h} \\
\text { Basic coverage } \\
\text { Urban: } 120 \mathrm{~km} / \mathrm{h} \\
\text { High speed } 350 \\
\mathrm{~km} / \mathrm{h}\end{array}$ \\
\hline Potion Accuracy & Not specified & $\begin{array}{l}\text { Location } \\
\text { Determination } \\
\text { latency: } 30 \mathrm{~s} \\
\text { Hand set based: } 50 \\
\text { m (67- percentile) } \\
\text { Network based: } \\
100 \mathrm{~m}(67 \\
\text { percentile), } 300 \mathrm{~m} \\
\text { (95 percentile) }\end{array}$ \\
\hline $\begin{array}{l}\text { IDEL to ACTIVE } \\
\text { State Transition }\end{array}$ & $390 \mathrm{~ms}$ & $50 \mathrm{~ms}$ \\
\hline IQOS Classes & $\begin{array}{l}\text { UGS,nrt } \\
\text { PS.ert PS, } \\
\text { rtPs.BE }\end{array}$ & $\begin{array}{l}\text { UGS, ,nrt PS.ert } \\
\text { PS, rtPs.BE }\end{array}$ \\
\hline
\end{tabular}

A Comparison between WiMAX and UMTS/HSDPA

WiMAX and UMTS/HSDPA(Universal Mobile Telecommunication System/High Speed Downlink Packet Access) are both system able to provide high data rates to several users. Although the main purpose is the same, there are some differences regarding technical issues used by each one of the system. Table V summarizes the main differences between them:

TABLE V. COMPARISON BETWEEN MWIMAX AND UMTS/HSDPA

\begin{tabular}{|l|l|l|}
\hline Attributes & Mobile WiMAX & UMTS/HSDPA \\
\hline Standards & IEEE 802.16e & WCDMA \\
\hline
\end{tabular}


INTERNATIONAL JOURNAL OF INNOVATIVE RESEARCH IN ELECTRICAL, ELECTRONICS, INSTRUMENTATION AND CONTROL ENGINEERING Vol. 3, Issue 3, March 2015

\begin{tabular}{|l|l|l|}
\hline $\begin{array}{l}\text { Duplex } \\
\text { method }\end{array}$ & TDD & FDD \\
\hline $\begin{array}{l}\text { Multiple } \\
\text { Access }\end{array}$ & SOFDMA & CDMA \\
\hline $\begin{array}{l}\text { Frequency } \\
(\mathrm{GHz})\end{array}$ & $2.5,3.5,5.8$ & 2 \\
\hline $\begin{array}{l}\text { Frame Size } \\
(\mathrm{ms})\end{array}$ & 5 & 2 \\
\hline Modulation & QPSK/16QMA/64QMA & QPSK/16QMA \\
\hline $\begin{array}{l}\text { DL PHY } \\
\text { Peak Data } \\
\text { Rate (Mbps) }\end{array}$ & $\begin{array}{l}31.68 \text { (For a 10 MHz } \\
\text { channel) }\end{array}$ & 14.4 \\
\hline $\begin{array}{l}\text { Coverage } \\
\text { (km) }\end{array}$ & Up to 5 km & $\begin{array}{l}\text { Typically 2 to 5 } \\
\text { km }\end{array}$ \\
\hline HARQ & Yes & Yes \\
\hline $\begin{array}{l}\text { Fast } \\
\text { Scheduling }\end{array}$ & Yes & Yes \\
\hline AMC & Yes & Yes \\
\hline
\end{tabular}

B. Comparison between IEEE 802.16m and LTE Advance in accordance to IMT-Advanced

IMT-Advanced is the ITU description for system beyond IMT-2000 as discussed in much detail earlier. In the previous the two main candidates for IMT-Advanced certification (LTE-Advanced and IEEE $802.16 \mathrm{~m}$ ) have been presented along with the steps taken to satisfy the requirements for IMT-Advanced. IEEE $802.16 \mathrm{~m}$ has similar performance capabilities as LTE-Advanced technologies. With 802.16e operators can deliver upwards of 3.5 bps today (35 Mbps per sector for a $10 \mathrm{MHz}$ channel) while $802.16 \mathrm{~m}$ and LTE will advance that to over 5.0 bits per hertz (greater than 100Mbps per sector for a $20 \mathrm{MHz}$ channel). In Table VII summarizes the some difference between the two technologies

TABLE VI. COMPARISON BETWEEN IEEE 802.16M AND LTE-ADVANCED

\begin{tabular}{|c|c|c|}
\hline Parameter & IEEE $802.16 \mathrm{M}$ & LTE-Advance \\
\hline $\begin{array}{l}\text { MIMO } \\
\text { Technique }\end{array}$ & $\begin{array}{l}\text { DL: upto } 8 \times 8 \\
\text { UL: upto } 4 x 4\end{array}$ & $\begin{array}{l}\text { DL: upto } 8 \times 8 \\
\text { UL: upto } 4 \times 4\end{array}$ \\
\hline Latency (ms) & $\begin{array}{l}\text { C-Plane: } 100 \\
\text { (Idle to Active) } \\
\text { U-Plane : } 10\end{array}$ & $\begin{array}{l}\text { C-Plane:50 } \\
\text { U-Plane :10 }\end{array}$ \\
\hline Duplex Scheme & $\begin{array}{l}\text { TDD,FDD and } \\
\text { HFDD }\end{array}$ & TDD,FDD \\
\hline $\begin{array}{l}\text { Mobility } \\
\text { Support }\end{array}$ & Up to $500 \mathrm{~km} / \mathrm{hr}$ & $\begin{array}{l}\text { Max at speed }<15 \\
\mathrm{~km} / \mathrm{hr} \text { High } \\
\text { Performance }(120 \\
\mathrm{km} / \mathrm{hr}) \text { Maintain link } \\
350 \mathrm{~km} / \mathrm{hr}\end{array}$ \\
\hline Modulation & $\begin{array}{l}\text { BPSK,QPSK, } \\
\text { 16QAM,64 } \\
\text { QMA, SC. }\end{array}$ & $\begin{array}{l}\text { QPSK,16QAM,64 } \\
\text { QMA }\end{array}$ \\
\hline $\begin{array}{l}\text { Multicarrier } \\
\text { Support }\end{array}$ & $\begin{array}{l}\text { Up to } 100 \mathrm{MHz} \\
\text { with channel } \\
\text { aggregation }\end{array}$ & $\begin{array}{l}100 \mathrm{MHz} \text { with } \\
\text { channel } \\
\text { aggregation. }\end{array}$ \\
\hline $\begin{array}{l}\text { Saleable } \\
\text { Bandwidth } \\
\text { support }(\mathrm{MHz})\end{array}$ & $\begin{array}{l}5,7,8.75,10,20 \\
\text { and } 40 .\end{array}$ & $20-100$ \\
\hline $\begin{array}{l}\text { Peak Spectral } \\
\text { Efficiency } \\
\text { bps/Hz }\end{array}$ & $\begin{array}{l}\text { DL: } 15(4 \times 4) \\
\text { MIMO } \\
\text { UL: } 6.75(2 \times 4) \\
\text { MIMO }\end{array}$ & $\begin{array}{l}\text { DL:30 (8X8) } \\
\text { MIMO } \\
\text { UL:15 }(4 \times 4) \\
\text { MIMO }\end{array}$ \\
\hline $\begin{array}{l}\text { Peak Data Rate } \\
\text { (Mbps) }\end{array}$ & $\begin{array}{l}\text { DL: } 1000 \text { (Low } \\
\text { mobility) } \\
\text { DL: } 100 \text { (High } \\
\text { mobility) } \\
\text { UL:130 }\end{array}$ & $\begin{array}{l}\text { DL:1000 } \\
\text { UL: } 500\end{array}$ \\
\hline
\end{tabular}

Copyright to IJIREEICE

DOI 10.17148/IJIREEICE.2015.3340

\begin{tabular}{|l|l|l|}
\hline Access Scheme & $\begin{array}{l}\text { DL:OFDMA } \\
\text { UL:OFDMA }\end{array}$ & $\begin{array}{l}\text { DL:OFDMA } \\
\text { UL: SC-OFDMA }\end{array}$ \\
\hline $\begin{array}{l}\text { Cell Edge } \\
\begin{array}{l}\text { Spectral } \\
\text { Efficiency } \\
\text { (bps/Hz) }\end{array}\end{array}$ & DL:0.09 $(2 \times 2)$ & UL:0.12 (4X4) \\
\hline
\end{tabular}

\section{CONCLUSION}

The demand for high speed broadband services set to grow constantly the ITU's Radio communication sector (ITU-R) came up with recommendation for the design of a new air interface which would support this growing demand. Such system would be considered 4G or IMT-Advanced from $3 \mathrm{GPP}$ and IEEE $802.16 \mathrm{~m}$. IEEE $\mathrm{WG}$ is developed new standard to meet the requirement for IMT-Advanced for $4 \mathrm{G}$ system. IEEE $802.16 \mathrm{~m}$ and LTE-Advanced are the two main candidate technologies submitted for IMT-Advanced certification. IEEE $802.216 \mathrm{~m}$ and LTE-Advanced would merge into one as they target IMT-Advanced status is quelled because towards $4 \mathrm{G}$ certification, both these standards share a great deal of similar technological aspects and will certainly both qualify for $4 \mathrm{G}$ status.

\section{ACKNOWLEDEMENT}

I would like to thank my parents and Ms. Anita Khanna from IT-GGV, Bilaspur for helping me in a great manner for making this paper in a good way.

\section{REFERENCES}

[1] IEEE Std 802.16e-2005, "IEEE Standard for Local and Metropolitan Area Networks Part 16: Air Interface for Fixed Broadband Wireless Access Systems," 2005.

[2] IEEE Std 802.16e-2005, “IEEE Standard for local and metropolitan area networks, Part 16: Air Interface for Fixed Broadband Wireless Access systems, amendment 2: physical and medium access control layers for combined fixed and mobile operation in licensed bands," Feb. 2006.

[3] Bo Li, Yang Qin, Chor Ping Low, Choon Lim Gwee, "A Survey on Mobile WiMAX, "IEEE Communication Magazine, vol. 45, issue: 12, pp. 70-75, Dec. 2007.

[4] Mai Tran, G. Zaggaulos ans A. Nix, "Mobile WiMAX MIMO Performances Analysis: Downlink and Uplink," IEEE PIMRC, Sept. 2008.

[5] O. Arafat, K. Dimyati, "Performance parameter of Mobile WiMAX: A Study on the physical layer of Mobile WiMAX under Different Communication Channels \& Modulation Technique," ICCEA Computer Engineering and Applications, vol. 2, pp. 533-537, April 2010.

[6] M. Tran, G. Zaggoulos, A. Nix, A. Doufexi, "Mobile WiMAX: Performance Analysis and Comparison with Experimental Results," Vehicular Technology Conference, IEEE Conferences, pp. 1-5, Sept. 2008.

[7] A. Makelainen, "Analysis of Handoff Performance in Mobile WiMAX Networks,” Dec. 2007.

[8] S.K Ray, K. Pawlikowski, H. Sirisena, "Handover in Mobile WiMAX Networks: The State of Art and Research Issues," Communication Survey \& Tutorials, IEEE Journal, vol. 12, issue 3, pp. 376-399, Aug. 2010.

[9] B. Zdenek, M. Pavel, B. Robert, "Initiation of Handover Procedure in WiMAX Networks," 2009.

[10] Wenhua Jiao, Pin Jiang, Yunayuan Ma, "Fast Handover Scheme for Real-Time Application in Mobile WiMAX," Communication, IEEE Conferences, pp. 6038-6042, June 2007.

[11] Y.A. Alqudah, Huiqin Yan, "On Handover Performance Analysis in Mobile WiMAX Networks," Mobile WiMAX Symposium, IEEE Conferences, pp. 20-23, Oct. 2009

[12] IEEE 802.16m-09/0034r2, “IEEE 802.16m System Description Document," Sept. 2009. 
[13] IEEE P802.16m/D5, “IEEE 802.16m Draft Amendement to IEEE Standard for Local and Metropolitan Area Networks," Arp. 2010.

[14] ITU-R M. 2134, "Requirements Related to Technical System Performance for IMT-Advanced Radio Interface," Nov 2008.

[15] S. Parkvall, E. Dahlman, A. Furuskar, "LTE-Advanced-Evolving LTE towards IMT-Advanced," Vehicular Technology Conference, IEEE Conferences, pp. 1-5, Sept. 2008.

[16] IEEE 802.16m-07/002r2, “IEEE 802.16m Requirements," 2007.

[17] IEEE 802.16m-07/037r2, "IEEE 802.16m Evaluation Methodology," 2007.

[18] Papapanagiotou, I., Toumpakaris, D., "A survey on Next Genration Mobile WiMAX Networks: objectives, featurs and technical challenges", vol. 11, issue 4, pp.3-18, Dec. 2009.

[19] Alasti, M.; NeekZad, B.; Jie Hui Vannithamby, R. "Quality of service in WiMAX and LTE networks", vol. 48, issue 5, pp. 104-111, May 2010.

[20] WiMAX forum,"WiMAX and IEEE 802.16m Air Interface Standard" April 2010.

[21] Chang, M. J.; Abichar, Z.; Chau-Yun Hsu; "WiMAX or LTE : Who will Leed the Broadband Mobile Internet? ”, vol. 12, issue 3, pp. 26-32, April 2010.

\section{BIOGRAPHIES}

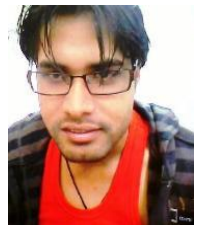

I am Deman Kosale, I did my B.Tech. from NIT Raipur, M.Tech from NIT Hamirpur (H.P) Specialization in signal processing and control engineering. I was working as a Engineer Trainee in BHEL Bhopal and Assistant Professor in Electrical Engineering Department, Institute of Technology, Guru Ghasidas Central University, Bilaspur (C.G.) and now presently working as a Assistant Professor in Electrical Engineering Department, Vishwavidhyslsys Engineering College, Lakhanpur, Sarguja University, Ambikapur (C.G.), India, My research interests lies in the field of Adaptive Signal Processing Neural Network and Fuzzy Logic, Control System , Mobile communication and Renewable Energy Resources I have Published lot of research papers and books .

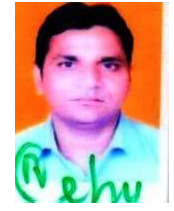

I am H.R.Suryawanshi, I did my MSc. From Govt. Model Autonomous Science PG College Sipat Road Bilaspur (C.G.)

in Mathamatics. I was working as a lecturer in Govt. polytechnic college korba (C.G.). now presently working as a Assistant Professor Department OF Mathamatics, Vishwavidhyslsys Engineering College, Lakhanpur, Sarguja University, Ambikapur (C.G.). My research interests lies in the field of discrete mathamatics and Neural Network and Fuzzy Logic.

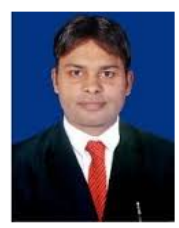

Mr. Maheedhar Dubey completed Master of Engineering in VLSI Design, currently working as an Assistant Professor in Electronics Engineering Department, Vishwavidyalaya Engineering College, Lakhanpur;Sarguja University Ambikapur, Chhattisgarh, India. He has 6 years of teaching experience in UG \& PG. He has published/communicated more than 8 publications in National/ International Journals and conferences. He is the member of four professional societies like IEI, ISTE, IETE, ISCA. His research interest includes VLSI, VHDL, Image processing and communication Engineering. 